\title{
Integration of quality improvement and cost-efficiency through industrial improvement techniques
}

LETTER

\section{Jasper P Vink' \\ Maxime T Rigaudy ${ }^{1,2}$ \\ Karl O Elmqvist' \\ 'Imperial College Business School, Imperial College London, London, ${ }^{2}$ Hull York Medical School, York, UK}

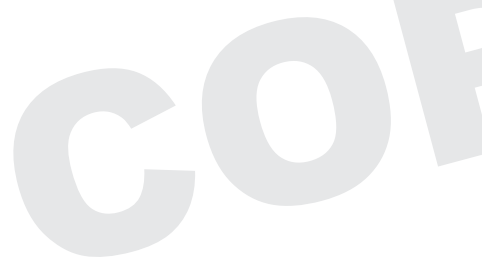

Correspondence: Jasper P Vink Imperial College London, Exhibition Road, South Kensington, SW7 2AZ London, UK

Email jasper.vink12@imperial.ac.uk
This article was published in the following Dove Press journal: Journal of Multidisciplinary Healthcare 24 June 2016

Number of times this article has been viewed

\section{Dear editor}

In this journal, Crema and Verbano ${ }^{1}$ discussed the importance of defining quality of health care and how quality can be improved through various industrial instruments and techniques. Quality of health care is a heavily debated topic that requires a wide scope of considerations across the many stakeholders of the health system. We acknowledge Crema and Verbano's arguments that patient safety is a basic pillar of quality, upon which we would like to expand by highlighting the clinical effectiveness and patient-reported outcomes, which are the two further crucial components of quality. The arguments made regarding quality improvement techniques and cost efficiency in health care provision are insightful, yet appear to make a distinction between efforts to improve quality, eliminate waste from processes, and cut costs in health care provision. We would argue that in fact these achievements are all closely related and can be achieved simultaneously, if the industrial techniques of quality management are applied adequately.

Crema and Verbano discuss the importance of focusing on increasing the quality first before addressing reliability and then focusing on cost efficiencies. ${ }^{1}$ Although this approach is appropriate in highlighting the significance of putting patient safety central in the delivery of health care, there are various limitations to this method as it sees these various improvements as separate processes to be undertaken. A more appropriate way of viewing quality improvement is as an integrated approach to improving safety, reliability, and efficiency in hospital processes, which in turn leads to cost reductions as an effect of the applied improvement strategies. This relies in part on the principle that increased quality in itself is associated with low costs due to the avoidance of litigation costs. Both Feigenbaum ${ }^{2}$ and Crosby $^{3}$ describe quality to relate to two distinct costs: conformance (or upholding quality) and nonconformance (or failures). In health care, costs of nonconformance often outweigh those of conformance, ${ }^{4}$ meaning investments in improving quality will inherently lead to lower overall costs for the system. In 2014, the NHS Litigation Authority paid out $£ 1.1$ billion to patients, indicating the huge financial burden that poor quality and patient dissatisfaction can incur on a health service. ${ }^{5}$ Changing health provision to 1) reduce medical error, 2) improve clinical outcomes, and 3) increase patient satisfaction will therefore inherently lead to cost reduction by the system. 
Usage of industrial techniques to improve process efficiency has proven to impact both the quality of health care provision and the cost efficiency. The Virginia Mason Medical Center in Seattle, WA, is renowned in the study of health care management for the use of industrial production techniques, specifically the Toyota Production System, to revolutionize the delivery of care at the hospital. Not only did this improve patient safety, in part due to the important patient safety alert system, but also crucially led to a huge capital saving of $>\$ 12$ million. ${ }^{4}$ This principle is also seen in Lean Six Sigma projects, which aim to remove waste and inefficiencies from processes. At the University Medical Center in Groningen, a Lean Six Sigma project for the coronary catheterization pathway led to a reduction of 500 inpatient bed days every year, and therefore, a large cost advantage for the organization. ${ }^{6}$

In conclusion, although we agree with the insightful views provided by Crema and Verbano regarding the definitions of clinical quality, we argue that quality and cost of care in the health sector are not separate factors that should be improved separately. Rather, we suggest that they are inherently inte- grated with one another, highlighted by Feigenbaum ${ }^{2}$ and Crosby's ${ }^{3}$ definitions of the costs of quality. This implies that industrial quality management techniques do not only lead to improved process efficiency and patient safety but also to measurable cost reductions.

\section{Disclosure}

The authors report no conflicts of interest in this communication.

\section{References}

1. Crema M, Verbano C. Future developments in health care performance management. J Multidiscip Healthc. 2013;6:415-421.

2. Feigenbaum A. Total quality control. Harv Bus Rev. 1956;34(6):93-101.

3. Crosby P. Quality Is Free: The Art of Making Quality Certain. 6th ed. New York, NY: McGraw-Hill; 1979.

4. Bohmer RMJ, Ferlins EM. Virginia Mason Medical Center. Brighton, Boston: Harvard Business School Publishing; 2005.

5. NHS Litigation Authority. NHS Litigation Authority Report and Accounts 2014/2015. London: NHS Litigation Authority; 2015.

6. Van Ede J [webpage on the Internet]. Lean Six Sigma makes UMCG more efficient and better. 2008. Available from: http://www.procesverbeteren.nl/ Lean_Six_Sigma/Lean_Six_Sigma.php. Accessed May 16, 2016. Dutch. 


\section{Authors' reply}

Maria Crema

Chiara Verbano

Department of Management and Engineering, University of Padova, Vicenza, Italy

Correspondence: Chiara Verbano

Department of Management and Engineering, University of Padova,

Stradella San Nicola 3, 36I00 Vicenza, Italy

Email chiara.verbano@unipd.it

\section{Dear editor}

It is a pleasure to have the opportunity to deepen the topic of quality management in health care. Thanks to the letter of Vink et al, it is possible for us to further exploit and clarify the concepts and the theories reported in the article, especially for what concerns the adoption and the development of new managerial approaches deriving from industrial sectors.

As reported in the article, in the literature, different strategies to achieve multiple performance improvements are discussed. Among them, the theory of sand cone suggests to pursue first the development of a system of high quality, before considering objectives of an other nature. It seems there is a sequence to be followed: quality, reliability, flexibility, timeliness of the service delivery, and finally costs. The latter can be obtained as a consequence of pursuing the other performance results.

A patient expects to solve its health problem following a specific clinical pathway. According to the theory of service management, ${ }^{1}$ this can be considered a "hygiene factor", as it is required and claimed by patients, but it is also taken for granted. If in the past, the provision of effective care could be sufficient to achieve the satisfaction of the patients and the other stakeholders, nowadays, the effectiveness and patient safety are not enough. The different health care stakeholders are now attributing greater importance also to other aspects. According to a broad definition of the quality in health care: a health care system has to be effective, efficient, timely, accessible, acceptable and patient-centered, equitable, and safe in order to be considered of high quality. ${ }^{2-4}$ As reported in the article and in other studies, ${ }^{5}$ all these dimensions of the concept of quality must be managed and improved.

For sure, cost of nonquality (costs of nonconformance) can be cut by managing clinical risks and avoiding errors. However, pursuing only safety improvements, without a comprehensive Clinical Risk Management (CRM) approach that would compare attended costs and benefits, could increase the expenditure for the development of a highly reliable system (costs of conformance). As explained by Porter, ${ }^{6}$ safety is just one aspect of the quality in health care; therefore, a focus only on its enhancement can lead to missing the real aim, that is the improvement of the overall delivery of care. Nowadays, health care systems have to face multiple challenge simultaneously, meeting the high levels requested for all the dimensions constituting the quality concept. Basically, broadening the definition of health care quality means overcoming the conflictual performance vision, which focuses attention and efforts on one type of performance instead of another, and going beyond the theory of sand cone, which suggests following different performances step by step, giving priorities among them. If efficiency is considered as a dimension of health care quality, also cost performance, like others, has to be considered at the base of the cone, destroying the establishment of priorities in pursuing multiple performance objectives. In order to satisfy the requirements of diverse stakeholders, developing a system of high quality entails being highly performing from multiple perspectives.

The adoption of a single managerial approach could be not sufficient to accomplish this goal. For this reason, at the end of the article, we stressed the need to investigate potential integrations among different managerial approaches, in order to take advantages from each of them. Figure 1 in the article reported in the article does not suggest a priority of intervention, but a combination of several quality attributes must be considered simultaneously. It is the multiplicity of the objectives to be pursued that fosters the development of integrated methodologies. Studying potential integrated managerial approaches, we identified connections and overlaps between Health Lean Management (HLM) and CRM. These methodologies, usually adopted alternatively, can be combined to improve the clinical process management. In the literature, ${ }^{7,8}$ there are HLM projects in which positive results in terms of patient safety have been obtained, in addition to efficiency increase. However, without following all the phases reported in the CRM implementation process (ISO 31000), some clinical risks could be not identified and thus not properly managed. In later research, Lean \& Safety projects (L\&S projects) have been analyzed and defined as HLM projects reporting patient safety improvements: ${ }^{9}$ they constitute a starting point for the development of an integrated methodology. The most advanced L\&S projects should pursue objectives of HLM and CRM and, adopting tools and practices of both approaches, they can reach results that are typical of both HLM and CRM. ${ }^{10}$ For example, in the case reported in Crema and Verbano, ${ }^{9}$ among the others, two objectives were aimed at reducing 
adverse events and at decreasing costs of drug supplying that are pursued simultaneously. In order to achieve the multiple defined goals, tools and practices of both HLM and CRM were adopted, such as incident reporting (to report all the incidents or adverse events), 5Whys (to identify the root causes of the problems), impact-effort matrix (to define the priorities of the interventions), one-piece flow (to streamline the process) ${ }^{9}$, leading to positive results in terms of different performances, organizational climate, and employees' satisfaction. In another L\&S project, ${ }^{11}$ the reduction in infection and its related costs was obtained conducting a process analysis during a Kaizen event in the Day Hospital of a Paediatric Oncohematology Unit. On the developed Value Stream Map, among the other wastes, also clinical risks were identified. Tools and practices of both approaches were then adopted to reduce wastes and errors, achieving multiple performance enhancements and, once again, suggesting the benefits of the integration of HLM and CRM.

In these studies, the relevance of a multidisciplinary team and of the existence of a shared culture within the entire hospital was underlined. This is aligned with the research of Porter ${ }^{6}$ that highlighted the value for patients that can be generated by the combined efforts of several interventions and multiple specialties.

Thanks to these cases, a contribution has been provided for the definition of guidelines to develop a synergistic methodology that, exploiting the advantages of both HLM and CRM, can allow pursuing high levels of different quality attributes at the same time. Following the results obtained from this new combined approach, the integration of additional relevant methodologies (eg, Lean Six Sigma), tools, techniques, and practice could be analyzed to assure the improvement of all the quality attributes.
However, even if the research stream emerging in the article is new and deserves other investigations, it demonstrates its relevance not only for the academic community but also for hospital managers, citizens, and other stakeholders requiring a health care system of high quality under different perspectives.

\section{Disclosure}

The authors report no conflicts of interest in this communication.

\section{References}

1. Johnston R. The determinants of service quality: satisfiers and dissatisfiers. Int J Serv Ind Manage. 1995;6(5):53-71.

2. World Health Organization [webpage on the Internet]. Quality of Care: A Process for Making Strategic Choices in Health Systems. WHO Regional Office for the Western Pacific; 2006. Available from: http:// www.who.int/management/quality/assurance/QualityCare_B.Def.pdf. Accessed October 14, 2013.

3. Agency for Healthcare Research and Quality [webpage on the Internet]. National Health Care Disparities Report. 2011. Available from: http:// www.ahrq.gov/research/findings/nhqrdr/nhqr11/nhqr11.pdf. Accessed October 14, 2013.

4. Institute of Medicine. Crossing the Quality Chasm: A New Health System for the 21st Century. Washington, DC: National Academy Press; 2001.

5. Arah OA, Westert GP, Hurst J, Klazinga NS. A conceptual framework for the OECD health care quality indicators project. Int $J$ Qual Health Care. 2006;18(suppl 1):5-13.

6. Porter ME. What is value in health care? N Engl J Med. 2010;363(26): 2477-2481.

7. Blackmore CC, Bishop R, Luker S, Williams BL. Applying lean methods to improve quality and safety in surgical sterile instrument processing. Jt Comm J Qual Patient Saf. 2013;39(3):99-105.

8. Michael CW, Naik K, McVicker M. Value stream mapping of the Pap test processing procedure. Am J Clin Pathol. 2013;139(5):574-583.

9. Crema M, Verbano C. How to combine Lean and Safety management in health care processes: a case from Spain. Saf Sci. 2015;79:63-71.

10. Crema M, Verbano C. Investigating the connections between health lean management and clinical risk management: insights from a systematic literature review. Int J Health Care Qual Assur. 2015;28(8): 791-811.

11. Crema M, Verbano C, Chiozza ML. First evidences from "lean \& safety" projects. Int J Qual Serv Sci. 2015;7(2/3):245-259. Dove Medical Press encourages responsible, free and frank academic debate. The content of the Journal of Multidisciplinary Healthcare 'letters to the editor' section does not necessarily
represent the views of Dove Medical Press, its officers, agents, employees, related entities or the Journal of Multidisciplinary Healthcare editors. While all reasonable steps have been taken
to confirm the content of each letter, Dove Medical Press accepts no liability in respect of the content of any letter, nor is it responsible for the content and accuracy of any letter to the editor.

\section{Publish your work in this journal}

The Journal of Multidisciplinary Healthcare is an international, peerreviewed open-access journal that aims to represent and publish research in healthcare areas delivered by practitioners of different disciplines. This includes studies and reviews conducted by multidisciplinary teams as well as research which evaluates the results or conduct of such teams or health- care processes in general. The journal covers a very wide range of areas and welcomes submissions from practitioners at all levels, from all over the world. The manuscript management system is completely online and includes a very quick and fair peer-review system. Visit http://www.dovepress.com/ testimonials.php to read real quotes from published authors. 